\title{
Early Effects of Lockdown in India: Gender Gaps in Job Losses and Domestic Work
}

\author{
Ashwini Deshpande ${ }^{1}$ \\ Published online: 6 October 2020 \\ (c) Indian Society of Labour Economics 2020
}

\begin{abstract}
India imposed one of the strictest lockdowns in the world to contain the spread of COVID-19 pandemic. According to the Stringency Index developed by the Blavatnik School of Government at the University of Oxford, by the 25th of March, 2020, India had already reached the highest possible level of stringency (index value $=100$ ). This involved a near-complete shutdown of all economic activity. What were the labour market implications of this shutdown? The first-order effects are evident in the massive increase in total unemployment. However, is the pandemic and its aftermath a great leveller? Are the labour implications of the lockdown gender neutral? How did the lockdown affect domestic time allocation, in particular time spent on domestic work and with friends? Were these changes gender neutral, given that the lockdown was gender blind?
\end{abstract}

keywords Covid-19 $\cdot$ Lockdown $\cdot$ Employment $\cdot$ Gender $\cdot$ India

\section{Background}

International evidence indicates that in absolute terms, more women are likely to face job losses than men. In India, we have to remember the pre-existing gender inequality in labour force participation rates and employment. Note that between 2004-05 and 2017-18, while gaps between men and women in educational attainment have narrowed considerably, gaps in labour force participation widened. Female Labour Force Participation Rate (FLFPR), stubbornly and persistently low in India over decades, has declined precipitously over the last 15 years. Will the already widening gender gap in work participation and employment widen further due to lockdown and recession? Are women already in the labour force (a small and declining proportion of working-age women) more vulnerable to job losses compared to men?

Ashwini Deshpande

ashwini.deshpande@ashoka.edu.in

1 Ashoka University, Sonipat, India 


\section{Data}

I investigate these issues in a recent paper (Deshpande 2020). ${ }^{1} \mathrm{I}$ investigate shifts in both employment patterns and time allocation at home using data from the Centre for Monitoring Indian Economy (CMIE)'s Consumer Pyramids Household Survey (CPHS) database, which is a private data provider, collecting weekly data at the national level since January 2016. It is a longitudinal data set covering 174, 405 households (roughly 10,900 households per week and 43,600 per month). Each household is followed three times per year.

Typically, papers on employment and labour market outcomes for India are based on surveys such as the official National Sample Survey (NSS), or the publicly available India Human Development Survey (IHDS). However, the most recent round of the former is only available for 2017-18, and for the latter for 2011-12. Thus, the CMIE CPHS data are currently the only national-level source for assessing changes in employment in real time, especially if we want to assess the immediate effect of the national lockdown which started in the last week of March 2020.

\section{Main results}

Comparing a sample of more than 43,000 individuals over four waves of high frequency nationally representative longitudinal data, the paper finds the following. Due to the pre-existing significant and widening gender gaps in LFPR and employment, the absolute number of men who lost employment (104 million) is larger than the absolute number of women who lost employment (17 million) in the first month of the lockdown. However, while pre-lockdown employment was the strongest predictor of post-lockdown employment, its effect was different for men and women. Women who were employed in the pre-lockdown phase were roughly 20 percentage points less likely to be employed in the post-lockdown phase.

India has amongst the most unequal gender division of household work globally. The gender gap in average hours spent on domestic work hours decreased in the first month of the lockdown, nationally as well as across most states, due to a shift in the male distribution of hours. The male distribution continues to be rightskewed, but the proportion of men doing between 0.5 and 4 hours of housework per day increased post-lockdown. The increase in hours by men is driven by increased male unemployment, i.e. men who were unemployed in April 2020 spent more time on housework, compared to men who were not unemployed. The time spent with friends decreased for both men and women, but relatively more for women.

\footnotetext{
${ }^{1}$ Deshpande, Ashwini, 2020. "The Covid-19 Pandemic and Lockdown: First Order Effects on Gender Gaps in Employment and Domestic Time Use in India", GLO Discussion Paper Series 607, Global Labor Organization (GLO). https://ideas.repec.org/p/zbw/glodps/607.html.
} 


\section{Conclusions}

The COVID-19 pandemic has often been described as a great leveller. In several countries, early evidence suggests that regardless of which sections of the population are more vulnerable to the disease, the impact of the lockdown and economic shutdown, which is the key pandemic control strategy everywhere, has been highly uneven, hitting the already vulnerable groups much harder. In this sense, the pandemic has exposed the many fault lines that lay beneath the surface across the world.

India, home to a third of the world's population, is no exception to this global pattern. Using four waves of longitudinal national data for roughly 40,000 households, this paper presents estimates for the early differential effects of the lockdown by estimating the probability of being employed in April 2020, the first month of the extremely stringent national lockdown relative to December 2019.

Due to the pre-existing significant and widening gender gaps in LFPR and employment, the absolute number of men who lost employment is larger than the absolute number of women who lost employment in the first month of the lockdown. However, even though pre-lockdown employment was the strongest predictor of post-lockdown employment, its effect was different for men and women.

While women have suffered disproportionately more job losses, risky, hazardous and stigmatized jobs are exclusively their preserve. All frontline health workers, the trinity that forms the backbone of the primary healthcare system-ASHA (Accredited Social Health Activists), ANM (Auxiliary Nurse and Midwife) and Anganwadi workers (the ICDS or Integrated Child Development Scheme workers), are women. Thus, for a very large number of women, the choice seems to be between unemployment and jobs that put them at risk of disease and infection and make them targets of vicious stigma.

India has amongst the most unequal gender division of household work globally. The last large government Time Use Survey was conducted by the Central Statistical Organisation of the Ministry of Statistics and Programme Implementation in 1998-99 across six states in India. The statistics from this survey are not comparable, but instructive. The survey found that men spend significantly more time on income earning and personal care (including leisure) activities compared to women. However, women spend 10 times as much time on household work, including unpaid work on family enterprises, compared to men (CSO 1999).

In this paper, comparing hours spent on domestic work pre- and post-lockdown, I find that for both men and women, the amount of time spent on housework increased post-lockdown. Middle-class Indians are heavily dependent on paid domestic helpers. Barring a small proportion of live-in helpers, most of these helpers could not show up for work, which implied that the domestic work burden of middle-class employers of household help increased. However, it is noteworthy that the gender gap in average hours spent on domestic work hours decreased in the first month of the lockdown. Given that this result is based on 1 month of data, whether this will persist or not will only be clear after data for subsequent months is available.

The first set of figures released by the CMIE for May 2020 (not yet available to researchers) revealed that in the month of May 2020, with a gradual re-opening 
of the economy, 21 million jobs got added to the low base of April 2020. This is a hopeful sign. Despite this, the April unemployment rate remained at a high rate of $23.5 \% .^{2}$ However, the early recovery in employment seen in May and June appears to be losing momentum in urban areas in July, but rural areas continue to recover. ${ }^{3}$

This indicates that the unemployment challenge is massive. To sustain the momentum in employment generation in the coming months, we need to see strong policies to provide employment and boost demand, in the absence of which job losses might mount, worsening the employment crisis. The results of this paper indicate that in addition to overall unemployment, pre-existing inequalities along gender and caste lines are likely to get reinforced, unless the specific contours of disadvantage are recognized and addressed.

Publisher's Note Springer Nature remains neutral with regard to jurisdictional claims in published maps and institutional affiliations.

\footnotetext{
${ }^{2}$ https://www.business-standard.com/article/opinion/21-million-jobs-added-in-may-120060101674_1. html.

${ }^{3}$ https://www.business-standard.com/article/opinion/the-june-recovery-and-beyond-120071301428_1. html. 